\title{
Revisão por pares aberta: análise das revistas open access
}

\author{
Eloísa C. Príncipe de Oliveira \\ Instituto Brasileiro de Informação em Ciência e Tecnologia \\ principe@ibict.br
}

\section{Como citar:}

OLIVEIRA, E. C. P. de. Revisão por pares aberta: análise das revistas open access. In: ABEC MEETING, 2, 2018, São Paulo. Anais... São Paulo: Associação Brasileira de Editores Científicos, 2018. p. 1-5.

http://dx.doi.org/10.21452/abecmeeting.2018.180

\section{RESUMO}

Apresenta um breve panorama das revistas de acesso aberto que adotam o sistema de revisão por pares aberta, cadastradas no Directory of Open Access Journals (DOAJ). Foram identificados 128 títulos, sendo a maioria publicada no Reino Unido. O Brasil está representado por apenas três títulos. A prevalência das revistas é escrita em inglês e enquadra-se na categoria das ciências da saúde/médicas, dispersas em suas múltiplas especialidades ou campos de atuação, como por exemplo, Ginecologia e Obstetrícia, Cardiologia e Oftalmologia. Apresentam-se também registradas revistas das outras áreas: Ciências Sociais e Humanas. Conclui-se que o sistema de revisão por pares é ainda muito pouco utilizado pelos diferentes editores e que há necessidade de estudos futuros baseados em outras plataformas, com o objetivo de identificar diferenças e semelhanças no uso desse procedimento, observando as especificidades das práticas das diferentes áreas do conhecimento.

Palavras-chave: Comunicação científica. Revisão por pares aberta. Revistas de acesso aberto. Directory of Open Access Journals (DOAJ).

\section{ABSTRACT}

Presents a brief overview of the open access journals that adopt the open peer review system, registered in the Directory of Open Access Journals (DOAJ). A total of 128 titles were identified, most of which were published in the United Kingdom. Brazil is represented by only three titles. Most of the journals are written in English and fall into the category of health / medical sciences, dispersed in their multiple specialties or fields of practice, such as Gynecology and Obstetrics, Cardiology and Ophthalmology. Also present are journals of the areas of Social Sciences and Humanities. It is concluded that the peer review system is still very little used by the different editors and that future studies based on other platforms are needed, with the objective of identifying differences and similarities in the use of this procedure, observing the specificities of the practices of the different knowledge areas.

Keywords: Scholarly communication. Open peer review. Directory of Open Access Journals (DOAJ). 


\section{INTRODUÇÃO}

Uma discussão recorrente no âmbito da comunicação científica refere-se ao sistema de avaliação por pares, também conhecido como peer review ou referee system. Esse sistema, de acordo com Coimbra Júnior (2003, p. 66) envolve:

[...] o emprego sistemático de peers (ou colegas), na assessoria aos editores das revistas na seleção dos artigos. A expectativa é de que esse sistema seja suficientemente sensível para detectar aqueles trabalhos realmente originais, com metodologias e análises capazes de, efetivamente, somarem-se aos conhecimentos acumulados em um determinado campo da ciência. Espera-se ainda que os revisores sejam capazes de apontar erros, omissões, além de eventuais conflitos de interesse e desvios da ética.

De acordo com Pessanha (1998), esse sistema surge em 1665, com o aparecimento das primeiras revistas científicas - Journal des Sçavans, na França, e Philosophical Transactions, na Inglaterra, mas somente a partir de 1753, que o sistema se formaliza, quando a Royal Society of London passa a responsabilizar-se formalmente pela avaliação dos textos publicados, através da figura de seu Secretário Henry Oldenburg, que se encarrega da organização da revista e dos membros do Conselho da Sociedade, responsáveis pela avaliação dos manuscritos. (PESSANHA, 1998, p. 226).

Basicamente são três os modelos de avaliação por pares:

- o simples cego (single-blind), quando apenas os revisores sabem quem são os autores;

- o duplo-cego (double-blind), quando nem o autor e o avaliador são identificados; e

- a revisão aberta (open review), quando o autor sabe que são os revisores e os revisores sabem quem são os autores.

Embora o sistema de revisão por pares tenha ampla disseminação e aceitação, ele também é considerado controvertido e muitos questionam sua legitimidade (OLIVEIRA, 2008). Dentre as principais falhas apontadas, pode-se citar:

[...] lentidão da avaliação por parte dos pareceristas, principal motivo pelo qual pesquisadores consideram o processo pouco sustentável; qualidade dos pareceres, o que leva artigos de má qualidade ou casos de plágio a passar pela avaliação; pareceres enviesados ou preconceituosos; e falta de transparência no processo. (NASSI-CALÒ, 2015, online).

Estudo realizado com editores de revistas brasileiras cadastradas no Portal Brasileiro de Publicações Científicas em Acesso Aberto (oasisbr), realizado por Vilas Boas (2017), identificou que a avaliação duplo cega é a mais utilizada e considerada a mais eficiente, cerca de $95 \%$, segundo os editores brasileiros pesquisados. As avaliações cega simples e aberta apresentam baixa representatividade na amostra.

Na pesquisa conduzida por Garcia e Targino (2017) com editores brasileiros da Ciência da Informação (CI) foi identificado que a maioria (67\%) se mostra disposta a adotar a open review, e que $60 \%$ acreditam que esse sistema pode atuar como 
elemento em prol da qualidade das revistas da área.

Segundo investigação realizada por Mulligan, Hall e Raphael (2013 apud NassiCalò, 2015a), a revisão aberta é considerada efetiva por $20 \%$ dos pesquisadores entrevistados, pois:

[...] assegura comentários honestos e menos corrosivos do que na revisão simples ou duplo-cego, envolvendo revisor e autor em um debate científico frutífero. Os que se opõem acreditam que ela encoraja revisores a ser pouco críticos, pode excluir revisores jovens e dá ao autor a oportunidade de influenciar o revisor, além de encorajar a disputa entre ambos. (MULLIGAN, HALL; RAPHAEL, 2013, apud NASSI-CALÒ, 2015a, online).

Nesse contexto, com o movimento da Ciência Aberta, cujo um dos pilares é a revisão por pares aberta, torna-se oportuno analisar quais as revistas de acesso aberto estão adotando esse procedimento nos artigos submetidos à publicação nas diferentes áreas do conhecimento.

Assim, este estudo buscou identificar as revistas em acesso aberto indexadas no Directory of Open Access Journals (DOAJ) que adotam o sistema de revisão aberta. Especificamente, pretende-se: a) identificar as revistas em acesso aberto indexadas no DOAJ que adotam o sistema de revisão aberta por pares; b) identificar os países de origem dessas publicações; c) identificar os idiomas das revistas; d) identificar os seus editores; e e) identificar as áreas de cobertura.

Esse Diretório é a principal plataforma de registro de revistas em acesso aberto e tem por objetivo aumentar a visibilidade e facilitar o uso de revistas científicas e acadêmicas de acesso aberto. Atualmente, o DOAJ possui 11643 revistas indexadas, em diferentes áreas do conhecimento, publicadas em 128 países. Seu objetivo principal é aumentar a visibilidade e acessibilidade das revistas de acesso aberto, revisadas por pares. O Brasil é o terceiro país com o número maior de títulos indexados no Diretório, representado por 1264 (11\%) revistas, depois do Reino Unido (1395) e Indonésia (1362).

\section{METODOLOGIA}

Esta pesquisa tem caráter descritivo- quantitativo. A pesquisa de títulos no DOAJ foi realizada em junho de 2018 , selecionando-se, na busca avançada (advanced search), os campos de tipo de documento (journals vs articles) - journals, país de publicação (country of publisher) - todos e avaliação por pares (peer review) - open peer review.

\section{RESULTADOS}

Na pesquisa realizada no DOAJ sobre o procedimento adotado na avaliação de trabalhos submetidos à publicação foram identificadas 128 revistas que adotam o procedimento de revisão por pares aberto o que equivale a somente $1 \%$ do total de revistas, o que implica em dizer que esse sistema tem, na amostra pesquisada, baixa adesão pelas revistas cadastradas no DOAJ. A maioria (47\%) adota o sistema duplo cego nos artigos submetidos.

O reduzido número de revistas que adotam o sistema de revisão por pares aberto, mesmo de revistas de acesso aberto, pode ser em decorrência "[...] de apego 
um tanto exacerbado à cultura da revisão cega." (GARCIA E TARGINO, 2017, sem paginação) e, conforme apontado pelo Council of Science Editors (CSE), a revisão aberta possui seus próprios dilemas:

O conhecimento dos nomes dos pareceristas pode torná-los objetos de animosidade ou comportamento vingativo e, consequentemente, os pareceristas podem tornar-se menos críticos e imparciais, especialmente ao julgarem o trabalho de seus colegas. Isso também pode ocorrer no sistema com mascaramento parcial, sobretudo em algumas especialidades nas quais os pesquisadores conseguem descobrir facilmente quem fez a avaliação. (COUNCIL OF SCIENCE EDITORS, 2017, p. 45).

A origem geográfica das revistas que adotam o sistema aberto está dispersa entre 23 países, sendo o Reino Unido responsável pela publicação de 88 títulos. Destaca-se que esse número está estreitamente relacionado ao publisher BioMed Central (BMC), que agrega a maioria das revistas identificadas na pesquisa. Outros editores como o Taylor \& Francis Group e HighWire Press também aparecem como publishers de revistas que adotam o sistema aberto. Os Estados Unidos da América aparecem com oito revistas, a Alemanha com cinco, a Espanha com quatro, o Brasil com três títulos e a Holanda e România possuem dois títulos cada um. As revistas brasileiras são: Journal of Human Growth and Development, Revista Outubro e Projetos e Dissertações em Sistemas de Informação e Gestão do Conhecimento.

A primeira é editada pela Universidade de São Paulo (USP). Sua periodicidade é quadrimestral e está indexada em várias bases de dados, como a base Scopus, Index Psi Periódicos (BVS-Psi), Literatura Latino-americana e do Caribe em Ciências da Saúde (LILACS), CLASE - Citas Latinoamericanas em Ciências Sociales y Humanidades, Sociological Abstracts, Social Services Abstracts, Linguistic \& Language Behavior Abstracts. A revista Outubro, da área das Ciências Sociais, é uma publicação do Instituto de Estudos Socialistas. Publica artigos e resenhas de livros referentes aos seguintes temas: Estado; Trabalho; Economia, Teoria, História; Arte e Cultura; Negros (as); LGBTs; Mulheres; Movimentos Sociais; Meio Ambiente; Questões Internacionais. A revista Projetos e Dissertações em Sistemas de Informação e Gestão do Conhecimento é editada semestralmente pela Faculdade de Ciências Empresariais (FACE), da Universidade FUMEC, com a finalidade de publicar e divulgar os projetos, dissertações e teses do Programa de Pós-Graduação em Sistemas de Informação e Gestão do Conhecimento. Esta última, não se enquadra como revista científica, pois divulga projetos de pesquisa em andamento e trabalhos concluídos dos cursos de mestrado e doutorado do Programa.

\section{CONSIDERAÇÕES FINAIS}

Conclui-se que o sistema de revisão por pares aberta é ainda muito pouco utilizado pelos diferentes editores e que há necessidade de estudos futuros baseados em outras plataformas, com o objetivo de identificar diferenças e semelhanças no uso desse procedimento, observando-se as especificidades das práticas das diferentes áreas do conhecimento. O movimento da Ciência Aberta tende a colaborar de forma direta com a adoção desse sistema nas práticas editoriais das revistas científicas, conforme já observado em várias publicações, como aquelas do grupo BMC, que são de livre acesso e adotam o sistema open review. A "reservada" apropriação desse sistema pela comunidade envolvida parece refletir a própria natureza da estrutura 
atual vigente do sistema geral de comunicação científica. O sucesso ou não desse modelo vai depender mais ainda do grau de consistência que puder ser alcançado entre os atores envolvidos, o perfil do periódico científico e as práticas da área à qual ele serve.

\section{REFERÊNCIAS}

COIMBRA JÚNIOR, C. E. A. Desafios à avaliação da literatura científica: a revisão pelos pares. Cadernos de Saúde Pública, Rio de Janeiro, v. 19, n. 5, p. 12241225, set./out. 2003. Disponível em: <http://www.scielo.br/scielo.php?script=sci arttext\&pid=S0102-311X2003000500001\&lng=pt\&nrm=iso\&tlng=pt>. Acesso em: 26 jul. 2018.

COUNCIL OF SCIENCE EDITORS. Diretrizes do CSE para promover integridade em publicações de periódicos científicos: atualização de 2012. Tradução Ana Maria Tomasevicius. São Paulo: ABEC Brasil, 2017. Disponível em: <https://www. abecbrasil.org.br/arquivos/whitepaper CSE.pdf>. Acesso em: 28 jun. 2018.

GARCIA, J. C. R.; TARGINO, M. das G. Open peer review sob a ótica de editores das revistas brasileiras da Ciência da Informação. In: ENCONTRO NACIONAL DE PESQUISA EM CIÊNCIA DA INFORMAÇÃO, 18. 2017, Marília. Anais... Marília, Unesp, 2017. Disponível em: <http://enancib.marilia.unesp.br/index.php/ xviiienancib/ENANCIB/paper/viewFile/19/824>. Acesso em: 30 de jun. 2018.

NASSI-CALÒ, L. A revisão por pares como objeto de estudo. SciELO em Perspectiva, Apr. 2015. Disponível em: <https://blog.scielo.org/blog/2015/04/24/ a-revisao-por-pares-como-objeto-de-estudo/>. Acesso em: 30 jun. 2018.

NASSI-CALÒ, L. Avaliação por pares: modalidades, prós e contras. SciELO em Perspectiva, mar., 2015a. Disponível em: <https://blog.scielo.org/ blog/2015/03/27/avaliacao-por-pares-modalidades-pros-e-contras/\#.W1H1dJKjC8>. Acesso em: 30 jun. 2018.

OLIVEIRA, E. C. P. de. A comunicação da ciência. Pesquisa Brasileira em Ciência da Informação e Biblioteconomia, João Pessoa, v. 3, n. 1, 2008. Disponível em: <http://www.periodicos.ufpb.br/ojs/index.php/pbcib/article/view/6104/3823>. Acesso em: 20 jun. 2018.

PESSANHA, C. Critérios editoriais de avaliação científica: notas para discussão. Ciência da Informação, Brasília, v. 27, n. 2, p. 226-229, maio/ago. 1998. Disponível em: <http://revista.ibict.br/ciinf/article/view/809/840>. Acesso em: 26 jul. 2018.

VILAS BOAS, R. F. A revisão por pares na visão dos editores das revistas de acesso aberto coletadas pelo Portal oasisbr. Reciis: revista eletrônica de comunicação e informação e inovação em saúde, Rio de Janeiro, v. 11, supl. nov. 2017. Disponível em: < https://www.reciis.icict.fiocruz.br/index.php/reciis/article/ view/1405>. Acesso em: 26 ul. 2018. 